\title{
A case of anhydrotic ectodermal dysplasia with hypogammaglobulinaemia and seizures
}

\author{
Joydeep Das ${ }^{1}$, Devdeep Mukherjee ${ }^{2}$, Ritabrata Kundu ${ }^{3}$, Prabal Chandra Niyogi ${ }^{4}$, Joydev Tudu $^{2}$
}

Sri Lanka Journal of Child Health, 2014: 43(2): 108-109

(Key words: Ectodermal dysplasia; immunodeficiency; Amelo-cerebro-hypohidrotic syndrome)

\section{Case report}

A 10 month old baby girl was admitted to our hospital in July 2012 with persistent fever over the last 4 months. Temperature chart maintained by the mother showed that her fever ranged from $100-103^{\circ} \mathrm{F}$ during this period. Baby was born in September 2011 and was apparently well without any episode of fever during the first 6 months of life. With the setting in of summer in March 2012, the baby showed a rise of body temperature without any sweating.

Her motor and socio-personal development were around six and five months respectively. On examination, she had generalized hypotonia with brisk tendon jerks.

In spite of persistent fever, her blood counts, erythrocyte sedimentation rate, C-reactive protein and procalcitonin were never high. Blood and urine cultures did not reveal any growth of organisms. Lumbar puncture was normal. Autoimmune profile, including serum ferritin and antinuclear antibody, was also inconclusive. Mantoux test was negative. Chest x-ray, echocardiography and ultrasonography of abdomen were normal. Magnetic resonance imaging of brain showed no structural abnormality.

Considering the absence of sweat secretion with such high fever, a diagnosis of anhidrotic ectodermal dysplasia was suspected. Pilocarpine iontophoresis was done. There was no production of sweat following this test. We did a skin biopsy to confirm the diagnosis. Skin biopsy showed thin and flattened epidermis with absence of sweat glands and hair follicles which was suggestive of anhidrotic ectodermal dysplasia. However, x-ray of mandible

\begin{tabular}{l}
\hline${ }^{1}$ Assistant Professor, ${ }^{2}$ Postgraduate Trainee, \\
${ }^{3}$ Professor, ${ }^{4}$ Deputy Director, Department of \\
Paediatric Medicine, Institute of Child Health, \\
Kolkata, West Bengal, India
\end{tabular}

(Received on 23 May 2013: Accepted after revision on 26 July 2013) showed evidence of dentition. She also had normal hair and nails.

Her CD4 count and percentage were normal with respect to age but immunoglobulin profile showed hypogammaglobulinaemia: IgG $<50 \mathrm{mg} / 100 \mathrm{ml}, \operatorname{IgA}$ $20 \mathrm{mg} / 100 \mathrm{ml}, \mathrm{IgM} 21 \mathrm{mg} / 100 \mathrm{ml}, \mathrm{IgE}<0.1 \mathrm{IU} / \mathrm{ml}$. Her $\mathrm{IgG}$ and $\mathrm{IgE}$ levels were considerably lower for age appropriate values, whereas her $\operatorname{IgA}$ and $\operatorname{IgM}$ levels were in the lower normal range.

The patient was thereafter discharged in a clinically stable condition after being administered immunoglobulin at $400 \mathrm{mg} / \mathrm{kg}$. She was however readmitted 14 days later with severe respiratory distress and high grade fever for 3 days. She was also having recurrent convulsions for 2 days prior to admission. Her blood counts and C-reactive protein were again within normal limits. Chest $\mathrm{x}$-ray was suggestive of bilateral pneumonia. Electroencephalogram was suggestive of seizure disorder. Baby was ventilated but died after 3 days.

\section{Discussion}

Ectodermal dysplasia is a hereditary disease characterized by a congenital dysplasia of one or more ectodermal structures and their accessory appendages. Common manifestations include defective hair follicles, eyebrows, frontal bossing with prominent supraorbital ridges, nasal bridge depression, and protuberant lips. Intra-orally, common findings are anodontia or hypodontia, conical teeth, and, consequently, generalized spacing. The patient may suffer from dry skin, hyperthermia, and unexplained high fever as a result of the deficiency of sweat glands as in our patient ${ }^{1}$. Our index case also had normal hairs. $X$ ray of mandible had evidence of dentition. There was no abnormality of nails.

Amelo-cerebro-hypohidrotic syndrome is a degenerative disease characterized by amelogenesis imperfecta, seizures, mental regression and yellow teeth due to defective enamel. So far, 19 cases have 
been reported. Abnormality of muscle tone and developmental delay, which are variable manifestations, were present in our patient. It is transmitted as an autosomal recessive trait. Hair and nails are normal in this syndrome ${ }^{2}$, as in our patient. Once diagnosed with ectodermal dysplasia, she was suspected to have Amelo-cerebro-hypohidrotic syndrome. Seizures usually occur after 11 months with abnormal electroencephalogram. Our patient had evidence of seizure disorder when she was admitted at 10 months of age. However, we were not able to do molecular studies to confirm the diagnosis. Hypogammaglobulinaemia has not been previously associated with the Amelo-cerebro-hypohidrotic syndrome.

Anhidrotic ectodermal dysplasia with immunodeficiency (EDA-ID) is characterized according to its various manifestations, which include ectodermal dysplasia, vascular anomalies, osteopetrosis, and diverse immunological abnormalities such as susceptibility to pathogens, impaired antibody responses to polysaccharides, hypogammaglobulinaemia, hyper-IgM syndrome, impaired natural killer cell cytotoxicity, and autoimmune diseases3. This is another possibility though hypotonia, development delay and seizures do not favour this diagnosis.

\section{References}

1. Itthagarun A, King NM. Ectodermal dysplasia: a review and case report. Quintessence International 1997; 28(9):595-602.

2. Kawai T, Nishikomori R, Heike T. Diagnosis and treatment in anhidrotic ectodermal dysplasia with immunodeficiency. Allergology International 2012; 61(2):207-17.

3. Nakamura M. Amelo-cerebrohypohidrotic syndrome. Ryoikibetsu Shokogun Shirizu 2001; 33:170-1 